\title{
The influence of "C-factor" and light activation technique on polymerization contraction forces of resin composite
}

\author{
Sérgio Kiyoshi ISHIKIRIAMA', Thiago Majolo VALERETTO², Eduardo Batista FRANCO², Rafael Francisco Lia \\ MONDELLI ${ }^{2}$
}

\author{
1- DDS, MSc, PhD, Assistant Professor, Department of Operative Dentistry, Endodontics and Dental Materials, Bauru School of Dentistry, University of São \\ Paulo, Bauru, SP, Brazil. \\ 2- DDS, MSc, student, Department of Operative Dentistry, Endodontics and Dental Materials, Bauru School of Dentistry, University of São Paulo, Bauru, SP, Brazil. \\ 3- DDS, MSc, PhD, Professor, Department of Operative Dentistry, Endodontics and Dental Materials, Bauru School of Dentistry, University of São Paulo, \\ Bauru, SP, Brazil. \\ 4- DDS, MSc, PhD, Associate Professor, Department of Operative Dentistry, Endodontics and Dental Materials, Bauru School of Dentistry, University of São \\ Paulo, Bauru, SP, Brazil.
}

Corresponding address: Prof. Thiago Majolo Valeretto - Departamento de Endodontia, Dentística e Materiais Dentários - Faculdade de Odontologia de Bauru - USP - Al. Dr. Octávio Pinheiro Brisolla, 9-75 - 17012-901 - Bauru - SP, Brasil - Phone: (0xx14) 32818961 - e-mail: thiagomajolo@msn.com

Received: November 8, 2010 - Modification: August 4, 2011 - Accepted: September 5, 2011

\section{ABSTRACT}

\begin{abstract}
O bjectives: This study evaluated the influence of the cavity configuration factor ("C-Factor") and light activation technique on polymerization contraction forces of a Bis-GMA-based composite resin (Charisma, Heraeus Kulzer). Material and Methods: Three different pairs of steel moving bases were connected to a universal testing machine (Emic DL 500): groups $A$ and $B-2 \times 2 \mathrm{~mm}(C F=0.33)$, groups $C$ and $D-3 \times 2 \mathrm{~mm}(C F=0.66)$, groups $E$ and $F-6 \times 2 \mathrm{~mm}(C F=1.5)$. After adjustment of the height between the pair of bases so that the resin had a volume of $12 \mathrm{~mm}^{3}$ in all groups, the material was inserted and polymerized by two different methods: pulse delay $\left(100 \mathrm{~mW} / \mathrm{cm}^{2}\right.$ for $5 \mathrm{~s}, 40 \mathrm{~s}$ interval, $600 \mathrm{~mW} / \mathrm{cm}^{2}$ for $\left.20 \mathrm{~s}\right)$ and continuous pulse $\left(600 \mathrm{~mW} / \mathrm{cm}^{2}\right.$ for $\left.20 \mathrm{~s}\right)$. Each configuration was light cured with both techniques. Tensions generated during polymerization were recorded by $120 \mathrm{~s}$. The values were expressed in curves (Force $(\mathrm{N}) \times \operatorname{Time}(\mathrm{s})$ ) and averages compared by statistical analysis (ANOVA and Tukey's test, $\mathrm{p}<0.05$ ). Results: For the $2 \times 2$ and $3 \times 2$ bases, with a reduced C-Factor, significant differences were found between the light curing methods. For $6 \times 2$ base, with high C-Factor, the light curing method did not influence the contraction forces of the composite resin. Conclusions: Pulse delay technique can determine less stress on tooth/restoration interface of adhesive restorations only when a reduced C-Factor is present.
\end{abstract}

Key words: Composite resins. Physical properties. Bis-GMA

\section{INTRODUCTION}

The development of adhesive restorative materials is the main characteristic of current Dentistry. Despite all technology applied in the development of composites, the presence of a polymeric matrix as a basic component of this type of material causes shrinkage during the light curing polymerization $^{8}$. The shrinkage of a composite resin is a natural molecular phenomenon and a consequence of monomer approximation during the polymeric chain formation ${ }^{19}$. The contraction forces originated inside the material are transmitted, in part, to the adhesive interface between the tooth and restoration, which may result in cusp deflexion ${ }^{15,21}$ and gap formation ${ }^{11}$. These gaps allow oral fluids and bacterial penetration that are the main factors producing clinical problems like marginal percolation, secondary caries and postoperative sensitivity ${ }^{2,19}$. To minimize the tensions of contraction forces during and after the polymerization process, it is important to know and to use the technical resources.

An important factor to reduce polymerization 
tensions is the cavity configuration factor. Some authors ${ }^{8}$ observed that the contraction tension in some chemically activated resins is related to the ratio of the adhesion area to the free area (called cavity configuration factor or "C-Factor"). The quantity of free area is directly proportional to the flow (or elastic deformation) of the material, relieving, in part, the stresses generated by the volumetric contraction. However, doubts still persist on the real importance of this factor over the contraction tensions of a light curing composite resin that has a shorter period to relieve the stresses.

Another important factor to control the stresses from polymerization contraction is the light intensity. A low light intensity increases the period that the resin remains with a low elasticity modulus (pre-gel phase), allowing molecular accommodation and relieving contraction tension ${ }^{10,13,17}$. In this way, techniques that modulate the polymerization process were developed to minimize contraction problems. One technique that has been recognized is the pulse delay: polymerization starts with a low light intensity during a short period, followed by a non-light interval and then conventional activation allowing reasonable conversion rates. The non-light interval gives some time for the pre-gel phase to be prorogated allowing the material to flow during the beginning of the polymerization reaction and relieving part of the tension generated by the resin contraction $^{12,14}$. Some authors ${ }^{9,13,21}$ have emphasized that this technique reduces the polymerization contraction forces when compared to the single pulse technique, enhancing the adhesive forces and does not reduce the superficial hardness ${ }^{24}$.

However these factors are interdependent and studies to determine the contribution of both factors combined on the adhesive interface tension are still required. The aim of the present study was to evaluate the forces generated during the polymerization contraction of a Bis-GMA based composite resin with an association of different cavity configurations (C-Factor) and light activation techniques, with constant volume.

\section{MATERIAL AND METHODS}

\section{Experimental design}

This in vitro study was performed involving 2 factors: C-Factor (in 3 levels) and light activation technique (in 2 levels). The quantitative response variable was the force $(\mathrm{N})$ generated during the composite resin polymerization.

The contraction forces of a hybrid composite resin (Charisma-Heraeus Kulzer- Headquarter Germany) during polymerization were recorded on a universal testing machine (EMIC DL500; EMIC, São José dos Pinhais, PR, Brazil). One pair of stainless steel bases $50 \mathrm{~mm}$ high $\times 2 \mathrm{~mm}$ long $\times 2 \mathrm{~mm}$ wide was used for groups A and B (C-Factor $=0.33$ ); another pair of bases $50 \mathrm{~mm}$ high $\times 3 \mathrm{~mm}$ long $\times 2$ $\mathrm{mm}$ wide for groups $\mathrm{C}$ and $\mathrm{D}$ (C-Factor $=0.66)$; and a pair of bases $50 \mathrm{~mm}$ high $X 6 \mathrm{~mm}$ long $X 2 \mathrm{~mm}$ wide was used for groups $E$ and $F(C-F a c t o r=1.5)$ (Figure 1 ). Each pair of bases was connected parallel to each other and the upper base was connected to a $50 \mathrm{Kg}$ load cell that was then connected to the moving arm of the testing machine. The lower base was connected to the fixed arm of the machine ${ }^{5}$.

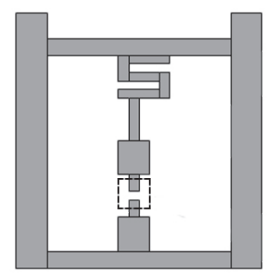

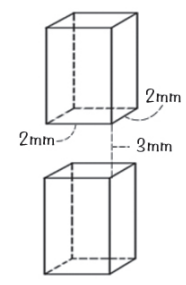

$A / B$

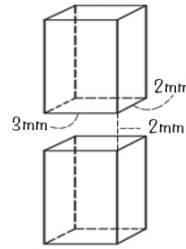

$C / D$

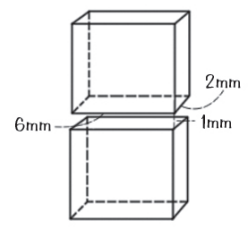

$E / F$
Figure 1- Schematic aspect of steel bases dimensions of all groups

After the distance adjustments were made between the bases to achieve a standardized volume of $12 \mathrm{~mm}^{3}$ for all samples, the composite resin was inserted in a single increment. A halogen light source with different periods and intensities (VIP; Bisco, California, USA) was used. Two polymerization techniques were used: 1 ) pulse delay (groups B, D, F): light activation for $5 \mathrm{~s}$ with $100 \mathrm{~mW} / \mathrm{cm}^{2}$ at $40 \mathrm{~s}$ intervals and light activation for $20 \mathrm{~s}$ with $600 \mathrm{~mW} / \mathrm{cm}^{2} ; 2$ ) continuous pulse (groups A, C, E): light activation for $20 \mathrm{~s}$ with $600 \mathrm{~mW} / \mathrm{cm}^{2}$. For each pair of bases, the composite resin was activated with the two light activation techniques and the experiment was carried out at $23^{\circ} \mathrm{C} \pm 2^{\circ}$.

Six specimens were obtained for each group, a total of 12 specimens for each pair of bases. During testing, the load cell recorded the forces generated by the polymerization contraction and data was recorded continuously during $120 \mathrm{~s}$ [graph Force (N) $x$ Time(s)]. The maximum values were statistically analyzed with two-way ANOVA (C-Factor and light activation technique) and individual differences were analyzed with Tukey test at $5 \%$ significance level. 
Table 1- Study groups, size of the bases, C-Factor, contraction forces $(\mathrm{N})$, light activation mode and statistical analysis

\begin{tabular}{cccccc}
\hline Groups & Bases & C- Factor & contraction forces $(\mathbf{N})$ & light activation technique & statistical analysis \\
\hline A & $2 \times 2$ & 0.33 & $14.98 \pm 0.24$ & continuous & $\mathrm{C}$ \\
B & $2 \times 2$ & 0.33 & $11.06 \pm 0.69$ & pulse delay & $\mathrm{A}$ \\
C & $3 \times 2$ & 0.6 & $13.71 \pm 0.71$ & continuous & $\mathrm{B}$ \\
D & $3 \times 2$ & 0.6 & $11.19 \pm 0.42$ & pulse delay & $\mathrm{A}$ \\
E & $6 \times 2$ & 1.5 & $15.88 \pm 0.85$ & continuous & $\mathrm{C}$ \\
F & $6 \times 2$ & 1.5 & $15.53 \pm 0.75$ & pulse delay & $\mathrm{C}$ \\
\hline
\end{tabular}

Different letters indicates statistically significant differences between groups $(p<0.05)$.

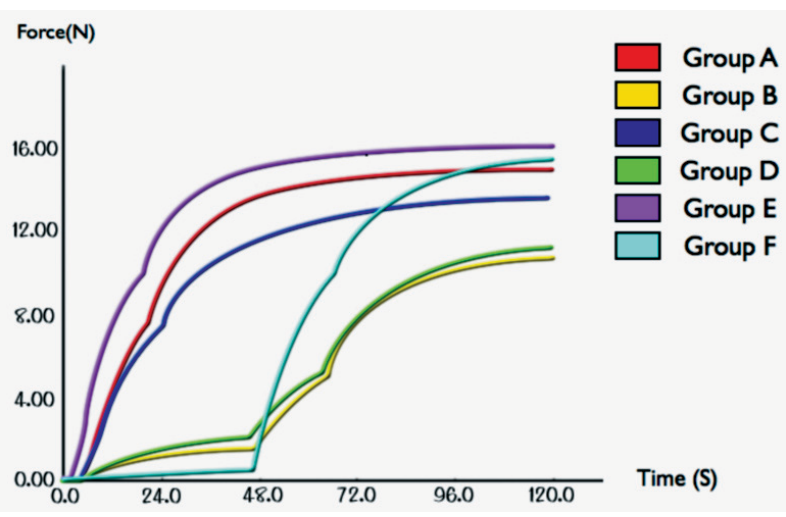

Figure 2- Shrinkage strain resulting from polymerization contraction of the experimental groups

\section{RESULTS}

The lowest stress values were recorded in groups $B$ and $D$, with bases $2 \times 2$ (C-Factor 0.33 ) and $3 \times 2$ (C-Factor 0.6 ). No statistically significant differences could be found for $6 \times 2$ (C-Factor 1.5) bases with any activation techniques (Table 1 ). The details of the results are presented (Figure 2), which shows the coefficient of near linear fit of contraction force/time, resulting in a plateau at the end of which the maximum shrinkage stress was recorded.

\section{DISCUSSION}

The C-Factor is related to the flow capacity of the composite resin based materials, which is an important phenomenon to relieve contraction tensions at tooth/restoration interface ${ }^{8}$. It has been observed that the higher the configuration factor, the higher the tension at the adhesive interface, independent of the volume increments in chemically activated resins ${ }^{8,22}$. To relieve these tensions there must be a considerably free area (low C-Factor) and a longer pre-gel phase allowing better resin flow and tension relief.

In the present study a constant volume of the composite resin and the pulse delay technique were used in groups $B$ and $D$, with bases $2 \times 2$ ( C-Factor 0.33 ) and $3 \times 2$ (C-Factor 0.6 ), and it was observed that the free surfaces allowed the flow of the composite resin, relieving part of polymerization tension with less contraction force (Table 1). These results are in accordance with other authors $4,16,20,23$. However, for groups $\mathrm{E}$ and $\mathrm{F}$, with higher C-Factors (1.5), which means larger areas of adhesive surfaces in relation to free surfaces, the contraction values were higher, regardless of the activation technique that was used. These results demonstrate the importance of C-Factors and similar observations have been reported ${ }^{6}$. It is important to highlight that the composite resin was inserted in one single increment, and for cavities with high C-Factor, it is recommended to use the incremental technique and light activation modulation to reduce the C-factor ${ }^{6}$.

In addition to the C-Factor, the light intensity can also influence the polymerization tension of the composite resin. For light activated composites, it is possible to reduce the velocity of the reaction without compromising the final polymerization by using lower intensity for longer periods of time ${ }^{19,23}$. This is possible because the polymerization conversion rate is related to the energy density absorbed by the composite $\left(\mathrm{mW} / \mathrm{cm}^{2} \times \mathrm{s}=\mathrm{mJ} / \mathrm{cm}^{2}\right)$, while the reaction velocity is related to the light intensity or power ${ }^{3}$.

There are different techniques for light activation of composite resins. Some authors have proposed an alternative technique, using low light intensity at the beginning to diminish the polymerization velocity, with better monomer accommodation and less tension, followed by the conventional technique to allow an adequate conversion rate ${ }^{12}$. The pulse delay allows a slow initial reaction, reducing the contraction forces ${ }^{14}$ and optimizing the marginal sealing, since less stress results in less gap formation ${ }^{1}$.

In the present study, the combination of pulse delay technique and low C-Factor resulted in lower contraction forces probably due to a better flow of the material during the pre-gel phase and a rearrangement of the polymeric chains ${ }^{21}$. For groups A, B, C and D with reduced C-Factors ( 0.33 and 0.6 , respectively), significant differences were found between the two light activation techniques, 
demonstrating that the polymerization technique is also important to relieve stresses resulting from the polymerization contraction when a sufficient free area is available. Authors that have compared the conventional and gradual light activation techniques found similar results that the gradual light activation did not compromise the bonding between tooth and restoration ${ }^{12}$. However, for $6 \times 2$ bases with higher C-Factor (1.5), the activation technique was not significant, thus demonstrating that the small free area that is present in this cavity configuration was not able to relieve the tensions.

Therefore, according to the results obtained in this study, the use of pulse delay technique for composite resin polymerization can result in restorations with less stress at the tooth/restoration adhesive interface. Furthermore, a free surface is required to allow the composite resin flow and consequent relief of the tension forces originated from the polymerization contraction. When small amounts of free surfaces are present to relieve these tensions (high C-Factor), even the pulse delay technique is not able to diminish the intensity of the contraction forces.

\section{CONCLUSION}

According to the results obtained in this study, it may be concluded that:

The pulse delay technique has positively influenced the relief and the magnitude of the contraction forces of the composite resin, only when a low C-Factor was present;

For a high C-Factor, the light activation technique was not capable of diminishing the contraction forces of the polymerization process.

\section{REFERENCES}

1- Asmussen E, Peutzfeldt A. Polymerization contraction of resin composite vs. energy and power density of light-cure. Eur J Oral Sci. 2005;113:417-21.

2- Bausch RJ. Clinical significance of polymerization shrinkage of composite resins. J Prosthet Dent. 1982;48:59-67.

3- Bouschlicher MR, Rueggeberg FA. Effect of ramped light intensity on polymerization force and conversion in a photoactivated composite. J Esthet Dent. 2000;12:328-39.

4- Bouschlicher MR, Vargas MA, Boyer DB. Effect of composite type, light intensity, configuration factor and laser polymerization on polymerization contraction forces. Am J Dent. 1997;10:88-96. 5- Castañeda-Espinosa JC, Pereira RA, Cavalcanti AP, Mondelli RFL. Transmission of composite polymerization contraction force through a flowable composite and a resin-modified glass ionomer cement. J Appl Oral Sci. 2007;15:495-500.

6- Charton C, Colon P, Pla F. Shrinkage stress in light-cured composite resins: influence of material and photoactivation mode. Dent Mater. 2007;23:911-20.
7- Deliperi S, Bardwell DN. An alternative method to reduce polymerization shrinkage in direct posterior composite restorations. J Am Dent Assoc. 2002;133:1387-98.

8- Feilzer AJ, De Gee AJ, Davidson CL. Setting stress in composite resin in relation to configuration of the restoration. J Dent Res. 1987;66:1636-9.

9- Hardan LS, Amm EW, Ghayad A, Ghosn C, Khraisat A. Effect of different modes of light curing and resin composites on microleakage of Class II restorations - Part II. Odontostomatol Trop. 2009;32:29-37.

10- Hofmann N, Denner W, Hugo B, Klaiber B. The influence of plasma arc vs. halogen standard or soft-start irradiation on polymerization shrinkage kinetics of polymer matrix composites. J Dent. 2003;31:383-93.

11- Ishikiriama SK, Mondelli RF, Kano SC, Ishikiriama A, Mondelli J. Role of additional retention on marginal adaptation and sealing of large resin composite Class II restorations. Oper Dent. 2007;32:564-70.

12- Kanca J $3^{\text {rd }}$, Suh BI. Pulse activation: reducing resin-based composite contraction stresses at the enamel cavosurface margins. Am J Dent. 1999;12:107-12.

13- Koran $P$, Kürschner R. Effect of sequential versus continuons irradiation of a light-cured resin composite on shrinkage, viscosity, adhesion, and degree of polymerization. Am J Dent. 1998;11:1722.

14- Lim BS, Ferracane JL, Sakaguchi RL, Condon JR. Reduction of polymerization contration stress for dental composites by twosteps light-activation. Dent Mater. 2002;18:436-44.

15 - Meredith N, Setchell DJ. In vitro measurement of cuspal strain and displacement in composite restored teeth. J Dent. 1997;25:331-7.

16- Mondelli RFL, Franco EB, Ishikiriama SK. Composite contraction polymerization forces: influence of volume and cavity configuration. In: $87^{\text {th }}$ General Session \& Exhibition of the IADR; 2007 March 24 ${ }^{\text {th }}$; New Orleans. Available from: <http:// iadr.confex.com/iadr/2007orleans/techprogram/abstract_93501. htm $>$.

17- Prati C, Nucci C, Davidson CL, Montanari G. Early marginal leakage and shear bond strenght of adhesive restorative systems. Dent Mater. 1990;6:195-200.

18- Rueggeberg FA, Caughman WF, Chan DC. Novel approach to measure composite conversion kinetics during exposure with stepped or continuous light-curing. J Esthet Dent. 1999;11:197205.

19- Sakaguchi RL. A review of the curing mechanics of composites and treir significance in dental applications. Compend Contin Educ Dent. $1999 ; 20: 16-23$.

20- Sakaguchi RL, Peters MC, Nelson SR, Douglas WH, Poort HW. Effects of polymerization contraction in composite restorations. J Dent. 1992;20:178-82.

21- Sakaguchi RL, Wiltbank BD, Murchison CF. Contraction force rate of polymer composites is linearly correlated with irradiance. Dent Mater. 2004;20:402-7.

22-Santos GO, Santos ME, Sampaio EM, Dias KR, Silva EM. Influence of $\mathrm{C}$-factor and light-curing mode on gap formation in resin composite restorations. Oper Dent. 2009;34:544-50.

23- Uno S, Asmussen E. Marginal adaptation of restorative resin polymerized at reduced rate. Scand J Dent Res. 1991;99:440-4. 24- Wang L, Garcia FC, Amarante de Araujo P, Franco EB, Mondelli RF. Wear resistance of packable resin composites after simulated toothbrushing test. J Esthet Restor Dent. 2004;16:303-14. 